\title{
EL CAMINO DE LA IGLESIA CATÓLICA EN MÉXICO HACIA LA LIBERTAD RELIGIOSA \\ Paolo Valvo*
}

RESUMEN: Al margen de la evolución sociopolítica y cultural que ha llevado a México del anticlericalismo exacerbado del Constituyente queretano a la reforma constitucional promovida por Carlos Salinas de Gortari en 1992, el conflicto mexicano entre el Estado y la Iglesia - particularmente en los años de la Guerra Cristera - ha contribuido de manera significativa a la evolución del pensamiento católico sobre la libertad religiosa en un nivel no solo nacional, sino universal.

$$
\text { গode }
$$

\section{The Catholic Church in Mexico: The Path Toward Religious Freedom}

ABSTRACT: Apart from the socio-political and cultural evolution that has led Mexico from the exacerbated anti-clericalism of the Constituent Assembly of Querétaro to the constitutional reform promoted by Carlos Salinas de Gortari in 1992, the conflict between the State and the Church in Mexico - especially during the Cristero War - has contributed significantly to the evolution of Catholic thought on religious freedom, at a level that is not only national, but also universal.

PALABRAS ClaVE: Concilio Vaticano II, conflicto Iglesia-Estado en México, Guerra Cristera, libertad religiosa.

KEY WORDS: Church-State Conflict in Mexico, Cristero War, Religious freedom, Vatican Council II.

RECEPCIÓN: 8 de marzo de 2018.

APROBACIÓN: 16 de mayo de 2018.

* Investigador posdoctoral en el Departamento de Historia Económica y Social y Ciencias de la Tierra Mario Romani, Universidad Católica del Sagrado Corazón de Milán. 
Se prohíbe su reproducción total o parcial por cualquier medio, incluido electrónico, sin permiso previo y por escrito de los editores. 


\section{EL CAMINO DE LA \\ IGLESIA CATÓLICA \\ EN MÉXICO HACIA LA \\ LIBERTAD RELIGIOSA}

E128 de septiembre de 2017, en la Pontificia Comisión para América Latina (con sede en Roma), tuvo lugar una conferencia para celebrar los veinticinco años de las relaciones diplomáticas entre México y la Santa Sede. Los ponentes subrayaron la excepcionalidad del aniversario para quien conoce la historia religiosa y política de este país, donde hace treinta años, según dijo en esta ocasión el embajador de México ante la Santa Sede Jaime del Arenal Fenochio, la mera hipótesis de una relación diplomática con el Vaticano era inimaginable. ${ }^{1}$ Inevitablemente, en el debate después de la conferencia se abordó la página más dramática del conflicto secular entre la Iglesia y el Estado, es decir, la Guerra Cristera. Otro embajador ante la Santa Sede de un país latinoamericano preguntó qué habían aprendido el Estado y la Iglesia de la experiencia de la Guerra Cristera. Me parece significativo empezar de aquí estas reflexiones, ya que la misma pregunta me ha acompañado en estos años de investigación, en los que me di a la tarea de reconstruir la actitud de la Santa Sede, y particularmente del pontífice Pío XI, frente a la rebelión armada de millares de católicos mexicanos contra el gobierno anticlerical de Plutarco Elías Calles.

A la luz de los documentos que se hallan en los archivos vaticanos, es posible afirmar que México fue objeto de una especial solicitud

${ }^{1}$ Jaime del Arenal Fenochio, "XXV años de relaciones diplomáticas entre México y la Santa Sede. El triunfo de la buena voluntad”, en Carità politica, XXII (2017), núm. 1-3, pp. 61-63. 
pastoral y eclesial de Pío XI durante su pontificado (1922-1939). ${ }^{2}$ Sería suficiente leer los documentos públicos del papa para darse cuenta de la centralidad del asunto mexicano en la geopolítica vaticana del tiempo ( si se puede utilizar este término) y más en general en la vida del catolicismo universal. ${ }^{3} \mathrm{~A} 1$ respecto escribió un historiador italiano que la cruzada contrarrevolucionaria de los cristeros, la persecución de los católicos y los violentos acontecimientos de la cuestión religiosa en México entre 1926 y 1929 permitieron al catolicismo latinoamericano salir de su histórico aislamiento para asumir un papel protagónico en el escenario del catolicismo universal. Por otro lado, siempre según el historiador, la crisis mexicana ha despertado el interés del catolicismo europeo por una Iglesia que hasta aquel tiempo se había encontrado profundamente descentrada. ${ }^{4} \mathrm{Si}$ esto ocurrió, se debió ante todo a la movilización de los católicos en todo el mundo que el pontífice promovió, sobre todo con sus encíclicas, es decir, la Iniquis afflictisque (18 de noviembre de 1926), la Acerba animi (29 de septiembre de 1932) y la Firmissimam constantiam (28 de marzo de 1937). Hay que mencionar otros documentos, como la carta apostólica Paterna sane (2 de febrero de 1926) y varias alocuciones consistoriales. Merece la pena subrayar que el interés de los católicos de todo el mundo por las vicisitudes de la Iglesia mexicana se ha vuelto, en medida creciente en los últimos diez años, un tema de investigación histórica particularmente fecundo para los expertos de historia transnacional ${ }^{5}$ y sigue proporcionando oportu-

${ }^{2}$ Véanse Alfonso Alcalá Alvarado, "Los acuerdos del 21 de junio de 1929 según el Archivo Secreto Vaticano: documentos", Efemérides Mexicana, XXVI (2008), núm. 78, pp. 413-439; Juan Carlos Casas García, "La documentación en el ASV sobre el conflicto religioso en México. La influencia en la Santa Sede de las diversas visiones del conflicto", ibid., pp. 441-470; Carmen José Alejos, "Pío XI y Álvaro Obregón. Relaciones a través de la Delegación Apostólica en México (1921-1923)", Anuario de Historia de la Iglesia, XXIII (2014), pp. 403-431; Paolo Valvo, Pio XI e la Cristiada. Fede, guerra e diplomazia in Messico (1926-1929), 2016, Brescia, Morcelliana.

${ }^{3}$ Juan González Morfín, El conflicto religioso en México y Pío XI, 2009, México, Minos; 1929-1929 Revolución silenciada. El conflicto religioso en México a través de las páginas de L'Osservatore Romano, 2014, México, Porrúa-Universidad Panamericana.

${ }^{4}$ Gianni La Bella, Roma e l'America Latina. Il resurgimiento cattolico sudamericano, 2012, Milán, Guerini, p. 218.

${ }^{5}$ Véanse Matthew Redinger, American Catholics and the Mexican Revolution (1924-1936), 2005, Notre Dame, University of Notre Dame; Jean Meyer, La cruzada por México. Los católicos 
nidades de investigación y de encuentro entre historiadores mexicanos, estadounidenses y europeos.

Además de los efectos más o menos inmediatos de los acontecimientos de un país sobre la sociedad civil de otros, es inevitable preguntarse, de todos modos, cuáles fueron los efectos nacionales e internacionales de largo plazo. De aquí volvemos a la pregunta inicial: ¿Qué aprendieron el Estado y la Iglesia católica de la lucha anticlerical que marcó con diferente intensidad la larga estación revolucionaria de México en el siglo XX? El análisis de todo lo que ocurrió en las décadas siguientes nos hace presumir que, en lo político, aprendieron por lo menos a respetarse y a convivir pacíficamente, hasta que en 1992 la reforma constitucional del presidente Carlos Salinas de Gortari cambió el marco legislativo y reconoció a la Iglesia católica y otras confesiones religiosas personalidad jurídica ante el derecho mexicano. ${ }^{6}$ Esto, sin embargo, no

de Estados Unidos y la cuestión religiosa en México, 2008, México, Tusquets; Id. (coord.), Las naciones frente al conflicto religioso en México, 2010, México, Tusquets; Marta Eugenia García Ugarte, "Jerarquía católica y laicos durante la Revolución: Enfrentamiento, disidencia y exilio político por su colaboración con el huertismo (1910-1914)", en Independencia y revolución: contribuciones en torno a su conmemoración, 2010, México, Instituto de Investigaciones Sociales-Universidad Nacional Autónoma de México; Massimo De Giuseppe, "Tra Lombardia e Messico: frammenti e incontri lungo il XX secolo", en María Matilde Benzoni y Ana María González Luna (coords.), Milano e il Messico. Dimensioni e figure di un incontro a distanza dal Rinascimento alla globalizzazione, 2010, Milán, Jaca Book, pp. 137-180; Stephen Andes, The Vatican and Catholic activism in Mexico and Chile. The politics of transnational Catholicism, 1920-1940, 2014, Oxford, Oxford University Press; Maurice Demers, Connected struggles. Catholics, nationalists, and transnational relations between Mexico and Quebec, 1917-1945, 2014, Montreal, Mc Gill-Queen's University Press; Julia Young, Mexican exodus. Emigrants, exiles and refugees of the Cristero War, 2015, Oxford, Oxford University Press; Hilda Iparraguirre, Massimo De Giuseppe, y Ana María González Luna (coords.), Otras miradas de las revoluciones mexicanas (1810-1910), 2015, México, Inah-Enah-Juan Pablos Editor; Yves Solís-Camille Foulard y Matthew Butler (coords.), Cruce de fronteras, t. I, Los católicos mexicanos y los católicos de Estados Unidos, t. II, Los católicos mexicanos y los católicos latinoamericanos, 2018, México, Universidad Autónoma Metropolitana Azcapotzalco-Centro de Estudios Mexicanos y Centroamericanos-LLILAS (en prensa). Entre las investigaciones más recientes se cuenta el proyecto de tesis doctoral Católicos mexicanos en el extranjero: la Unión Internacional de Todos los Amigos (VITA México), 1925-1934, de Ariadna Guerrero Medina, Instituto de Investigaciones Dr. José María Luis Mora.

${ }^{6}$ Raúl González Schmal, Derecho eclesiástico mexicano. Un marco para la libertad religiosa, 1997, México, Porrúa, pp. 199-251; José Luis Soberanes Fernández, El derecho de libertad religiosa en México (un ensayo), 2001, México, Porrúa-Comisión Nacional de los Derechos 
implica necesariamente que México se haya reconciliado con los aspectos más controvertidos de su historia. Por lo contrario, muchas de las narrativas mutualmente excomulgadoras (si así podemos llamarlas) sobre los actos de la Iglesia y del Estado en la historia moderna y contemporánea de México siguen en pie.

Es útil comparar la situación mexicana con la de Italia, donde también hubo dificultades por obra de visiones de la historia nacional excesivamente esquemáticas y maniqueas impulsadas, por un lado, por laicistas anticlericales, que siempre vieron a la Iglesia católica como un obstáculo para la unificación nacional y la modernización del país, y por el otro, por los sectores más integristas del catolicismo italiano, que tal vez parecían no aceptar el hecho histórico del proceso de unificación decimonónico, a pesar de los aspectos anticlericales que sin duda tuvo. La necesidad de una memoria histórica compartida repercute todavía en otros acontecimientos cruciales de la historia italiana, como la guerra civil de 1943-45, entre los italianos que seguían manteniéndose fieles al duce Benito Mussolini (apoyado por los alemanes) en el marco de la República Social Italiana y los que, en el norte del país, combatían contra los fascistas y los mismos alemanes (en la resistenza), mientras que en el sur (ya ocupado por los aliados angloestadounidenses) seguía vigente 14 la monarquía legitima de Víctor Manuel III, aunque desprestigiada. Italia, al igual que México, tiene una historia compleja y difícil de abordar, pese a todos los esfuerzos ideológicos y políticos hechos en la posguerra para acotar un "pasado tan pesado".

Ahora bien, una diferencia sustancial entre los dos países con respecto al papel histórico de la Iglesia católica es que en Italia, después de la crisis del régimen liberal y el fin de la dictadura fascista, hubo una plena legitimación política y jurídica del catolicismo como elemento irrenunciable de la sociedad y de la identidad nacional, en el marco del nuevo Estado democrático y republicano, ya que en 1929 los Pactos de Letrán entre Italia y Santa Sede sí habían sanado la fractura de la llamada "cuestión romana", pero en el marco político de una dictadura

Humanos, pp. 34-40 y 55-73; José Antonio González Fernández, José Francisco Ruiz Massieu y José Luis Soberanes Fernández, Derecho eclesiástico mexicano, 2008, México, Porrúa, pp. 3-64 y 107-314. 
totalitaria. ${ }^{7}$ Este proceso tuvo una definitiva sanción jurídica con el Congreso Constituyente de 1946-1947, en el que los diputados del partido de la Democracia Cristiana - que ya en aquel entonces tenía la mayoría relativa de los sufragios - cumplieron un papel protagónico en el diseño del nuevo Estado, a partir de los principios de una democracia orgánica con un fuerte contenido social que tendría que acabar definitivamente con el liberalismo decimonónico. ${ }^{8}$ Como prueba de la plena legitimación de la Iglesia católica, cabe mencionar que en el artículo 7 de la Constitución italiana del $1^{\circ}$ de enero de 1948 — todavía vigente- se hizo una mención explícita a los Pactos de Letrán de 1929 como marco normativo de las relaciones entre el Estado y la Iglesia, ${ }^{9}$ y que esta mención fue aprobada con el voto determinante de los constituyentes del Partido Comunista Italiano, que en aquel entonces era ya quizás el partido marxista más fuerte de Occidente.

En México, al contrario, la Constitución de 1917 (de cuyo texto original queda solo un porcentaje mínimo, debido a las más de 200 reformas que la han afectado en sus primeros cien años $)^{10}$ no reconoció a la Iglesia, sino que, en realidad, la desconoció como entidad

${ }^{7}$ Francesco Margiotta Broglio, Italia e Santa Sede dalla grande guerra alla conciliazione. Aspetti politici e giuridici, 1966, Bari, Laterza y Roberto Pertici, Chiesa e Stato in Italia dalla Grande Guerra al nuovo concordato (1914-1984), 2009, Boloña, Il Mulino.

${ }^{8}$ Maria Bocci, Oltre lo Stato liberale. Ipotesi su politica e società nel dibattito cattolico tra fascismo e democrazia, 1999, Roma, Bulzoni, pp. 335-438.

${ }^{9}$ Véanse Giovanni Sale, Il Vaticano e la Costituzione, 2008, Milán, Jaca Book y Romeo Astorri, "I cattolici alla Costituente. Per una lettura del loro contributo sui rapporti fra Chiesa e Stato", en Maria Bocci (coord.), "Non lamento, ma azione". I cattolici e lo sviluppo italiano nei 150 anni di storia unitaria, 2013, Milán, Vita e Pensiero, pp. 347-359.

${ }^{10}$ Afirma José María Soberanes Diez: "México destaca por la cantidad de modificaciones formales a su Constitución vigente desde 1917. Hasta el 31 de diciembre de 2014 existen 218 decretos de reforma constitucional, a las que deben sumarse 13 fes de erratas y 2 aclaraciones, con lo cual tenemos 233 versiones distintas del texto fundamental. Si consideramos que en cada decreto pueden reformarse varios artículos, y sumamos cada cambio a un precepto, tenemos más de seiscientas modificaciones. [...] Si hacemos un análisis más amplio, podemos advertir que de los 1,562 párrafos que tiene actualmente la Constitución solo 45 son originales; es decir, un $2.88 \%$ pervive desde 1917 . Si consideramos que los párrafos pueden ser de distinto tamaño, habrá que analizar el número de palabras, de donde desprendemos que de las 60491 palabras que tiene la Constitución en la actualidad, solo 1538 son originales, lo que representa el 2.54\%". José María Soberanes Diez, Análisis formal de las reformas constitucionales, 2015, México, Universidad Nacional Autónoma de México-Instituto de Investigaciones Jurídicas-Consejo Nacional de Ciencia y Tecnología, pp. 1-3. 
jurídica y la sometió a un marco legal que en muchos aspectos era persecutorio. Hoy el artículo 130, reformado en 1992 junto con los artícu$\operatorname{los} 3^{\circ}, 5^{\circ}, 24$ y 27 , afirma que las relaciones entre el Estado y las confesiones religiosas se fundan sobre el "principio histórico de la separación entre el Estado y las iglesias". Es una afirmación que despierta curiosidad en el historiador, ya que en la historia contemporánea de México, al menos desde 1917 (y en ciertos aspectos desde la constitucionalización de las Leyes de Reforma en 1873), no se pudo hablar de una separación entre dos entidades, sino de la sumisión de una a la otra, como reconocieron, entre otros, y al margen del proceso de reforma constitucional, legisladores destacados del Partido Revolucionario Institucional como José Luis Lamadrid Sauza ${ }^{11}$ y José Francisco Ruiz Massieu. ${ }^{12}$

Si el desarrollo político y jurídico de México ha dejado parcialmente intacto el problema de una memoria histórica reconciliada con su pasado (sin negar los avances que la historiografía mexicana e internacional ha producido en las últimas décadas), también es posible afirmar que la experiencia de la lucha mexicana entre el Estado y la Iglesia ha contribuido de manera significativa a la evolución del pensamiento católico sobre la libertad religiosa no solo en el país, sino en

11 "En enero de 1917, el Constituyente emitió un dictamen según el cual resultaba necesario ir más allá del esquema de una mera separación de la Iglesia y el Estado, que había establecido la Reforma, y 'ampliar el punto de vista de las leyes en esta materia'. Lo era, en virtud de que la permisividad de las formulas anteriores dejaron 'a las agrupaciones religiosas en una completa libertad para acumular elementos de combate que, a su debido tiempo, hicieron valer contra las mismas instituciones a cuyo amparo habían medrado'. De ahí que se abandonara la declaración de que la Iglesia y el Estado eran independientes entre sí, porque ello significaba reconocer la personalidad de la Iglesia. El único camino viable, según el Constituyente de Querétaro, residía en la sencilla negación de la personalidad jurídica de las iglesias, puesto que solo de esa manera se restringiría el fenómeno religioso al ámbito estrictamente individual y se eliminaría, así, el poder político del clero. [...] Las disposiciones de la Constitución de 1917, que sustituyeron el principio de la separación entre el Estado y la Iglesia por el principio de la supremacía del Estado sobre las iglesias, fincaron las bases para la solución definitiva del conflicto religioso y orientaron, por la vía de la secularización, el avance hacia la modernidad de nuestra vida social.” José Luis Lamadrid Sauza, La larga marcha a la modernidad en materia religiosa, 1994, México, Fondo de Cultura Económica, pp. 23-26.

12 "En lo político, la Constitución de 1917 confirmó las soluciones del republicanismo demoliberal, como la división de poderes, el Estado de derecho, el Juicio de Amparo, las garantías individuales, el arreglo bicameral y el federalismo. También confirmó el municipio libre y se fue por la sujeción de las iglesias al Estado y el anticlericalismo." José Francisco Ruiz Massieu, El proceso democrático de México, 2a. ed., 1994, México, Fondo de Cultura Económica, p. 25. 
términos universales. ${ }^{13}$ Hoy, las frecuentes intervenciones del pontífice o de sus más cercanos colaboradores en pro del derecho a la libertad religiosa y contra la que el papa Francisco llama "la globalización de la indiferencia" son normales ${ }^{14}$ y coherentes con lo que la Iglesia concibe como su misión evangelizadora, después del Concilio Vaticano II. Sin embargo, sabemos que antes de la encíclica Pacem in terris de Juan XXIII ${ }^{15}$ y, sobre todo, de la declaración conciliar sobre la libertad religiosa Dignitatis humanae del 7 de diciembre de 1965, la Iglesia católica, aunque admitiendo — con Pío XII — la existencia de "derechos fundamentales de la persona", entre los que destaca "el derecho al culto de Dios privado y público, incluida la acción caritativa religiosa", ${ }^{16}$ no se había alzado como defensora explicita de la libertad religiosa, y más bien se limitaba a aceptar la tolerancia religiosa como mal menor en el marco de las modernas sociedades democráticas. ${ }^{17}$ En vísperas del Concilio, el horizonte conceptual prevalente en la Santa Sede (y en la Iglesia mexicana también) ${ }^{18}$ era el de la libertas Ecclesiae ("libertad de la Iglesia"), ${ }^{19}$ aunque la definitiva aceptación por parte del magisterio pontificio del sistema político democrático como el más adecuado

${ }^{13}$ Paul-Richard Gallagher, "La Santa Sede e la difesa del diritto alla libertà religiosa da Pio XI a Francesco", Conferencia magistral en el marco del Coloquio internacional Dalla Cristiada alle sfide dell'attualità. Il cammino della libertà religiosa, promovido por la Universidad Católica del Sagrado Corazón y la Universidad Panamericana, Milán, 30 de marzo de 2017.

${ }^{14}$ Giorgio Feliciani, "Papa Francesco e la libertà religiosa”, La Nuova Antologia, 617 (2016), pp. 82-94.

${ }^{15}$ José Martín de Agar, “A quarant'anni dalla Pacem in terris: I nuovi segni dei tempi”, La Società, 6 (2003), pp. 239-251.

${ }^{16}$ Pío XII, Radiomensaje de Navidad, Ciudad del Vaticano, 24 de diciembre de 1942, § 34, en $<$ https://w2.vatican.va/content/pius-xii/es/speeches/1942/documents/hf_p-xii_spe_19421224_ radiomessage-christmas.html $>$, consultado el 8 de marzo de 2018.

${ }^{17}$ Pío XII, Discorso ai giuristi cattolici italiani, Ciudad del Vaticano, 6 de diciembre de 1953, en $<$ https://w2.vatican.va/content/pius-xii/it/speeches/1953/documents/hf_p-xii_spe_19531206_ giuristi-cattolici.html>, consultado el 8 de marzo de 2018.

${ }^{18}$ Para una mirada sobre la Iglesia en México a lo largo del Concilio, véase Juan Carlos Casas García, "La Iglesia en México durante el Vaticano II: el contexto nacional y eclesial y la participación de los obispos mexicanos en el Concilio", en Efemérides Mexicana, XXXIII (2015), núm. 97, pp. 19-77.

${ }^{19}$ Una mirada sobre el cambio de la perspectiva católica con respecto a la libertad religiosa se encuentra en Ernst-Wolfgang Böckenförde, Cristianesimo, libertà, democrazia, 2007, Brescia, Morcelliana, pp. 35-80. 
a la dignidad intrínseca de cada ser humano (sancionada por los mensajes radiales del mismo Pío XII pronunciados entre 1942 y 1944) ya había puesto un fundamento sólido para reconocer la libertad como derecho natural subjetivo, ${ }^{20}$ lo que llevaría al abandono de una visión en la que, según la enseñanza tradicional de los pontífices del siglo XIX, solo la verdad tenía derecho a la libertad. ${ }^{21}$ ¿Qué tiene a que ver entonces la historia de la Guerra Cristera, que transcurrió completamente en el marco de la Iglesia preconciliar, con el tema de la libertad religiosa así concebida?

Una primera respuesta se encuentra quizá en la misma declaración conciliar Dignitatis humanae, en la que, entre las varias referencias a las escrituras y al magisterio precedente (particularmente la Pacem in terris), se hace referencia a dos encíclicas de Pío XI, es decir, la Mit brennender Sorge (14 de marzo de 1937) sobre la situación de la Iglesia en Alemania bajo el régimen nacionalsocialista hitleriano, y la Firmissimam constantiam (28 de marzo de 1937), sobre la situación de la Iglesia en México. En la primera el pontífice afirma que "el creyente [sin especificar su afiliación religiosa, católica o protestante] tiene un derecho inalienable a profesar su fe y a practicarla en la forma más conveniente a aquella. Las leyes que suprimen o dificultan la profesión y la práctica de esta fe están en oposición con el derecho natural". ${ }^{22}$ En lo que se refiere al caso mexicano, en el documento conciliar se afirma que "la Iglesia reivindica para sí la libertad, en cuanto es una sociedad de hombres, que tienen derecho a vivir en la sociedad civil según las normas de la fe cristiana", ${ }^{23}$ se refiere al pasaje de la Firmissimam constantiam en el

${ }^{20}$ A este propósito, véase Paolo Carozza-Daniel Philpott, The Catholic Church, human rights, and democracy: Convergence and conflict with the modern State, Notre Dame Law School-Scholarly Works, Paper 882, 2012, en <http://scholarship.law.nd.edu/law_faculty_ scholarship/882>, consultado el 8 de marzo de 2018.

${ }^{21}$ En 1948, por ejemplo, en el periódico jesuita La Civiltà Cattolica se afirmaba todavía que "la Iglesia católica, convencida — en virtud de sus prerrogativas divinas - de ser la única verdadera Iglesia, tiene que reivindicar para sí misma el derecho exclusivo a la libertad, ya que este derecho corresponde únicamente a la verdad, y nunca al error"; La Civiltà Cattolica, IC (1948), II, p. 35.

${ }^{22}$ Pío XI, Carta encíclica Mit brennender Sorge sobre la situación de la Iglesia católica en el Reich alemán, Ciudad del Vaticano, 14 de marzo de 1937, en $<\mathrm{http}: / /$ w2.vatican.va/content/pius-xi/es/encyclicals/documents/hf_p-xi_enc_14031937_mit-brennender-sorge.html>, consultado el 8 de marzo de 2018.

${ }^{23}$ Declaración Dignitatis humanae sobre la libertad religiosa, Ciudad del Vaticano, 7 de diciembre de 1965, §13, en <http://www.vatican.va/archive/hist_councils/ii_vatican_council/ documents/vat-ii_decl_19651207_dignitatis-humanae_sp.html>, consultado el 8 de marzo de 2018. 
que se afirma que "la Iglesia, por ser una sociedad de hombres, no puede existir ni desarrollarse si no goza de libertad de acción, y sus hijos tienen derecho a encontrar en la sociedad civil posibilidades de vivir en conformidad con los dictámenes de sus conciencias". ${ }^{24}$ La que se plantea en este punto es la libertad como ausencia de obstáculos por parte de las autoridades civiles para el desenvolvimiento la vida de la Iglesia en el espacio público. No cabe duda de que en México la lucha de los católicos contra el Estado se centró sobre la defensa de la libertad religiosa en este sentido, y es significativo al respecto que la organización que quiso federar las principales agrupaciones del laicado católico y, poco después, pretendió encabezar la rebelión armada de los cristeros, escogió llamarse Liga Nacional Defensora de la Libertad Religiosa. Sin embargo, hay otro sentido de la libertad religiosa, subrayado por la declaración conciliar y de cierto modo anticipado por la encíclica alemana Mit brennender Sorge y el magisterio de Pío XII, es decir la libertad religiosa como derecho de todos — no únicamente de los católicos- a buscar la verdad sin que nada y nadie pueda coartar su conciencia. Preguntémonos: ¿Los cristeros y la Iglesia mexicana en general pugnaron para que fuera reconocida la libertad religiosa también de los que compartían otros credos?

A la luz de la historiografía y de la documentación disponible ahora parece difícil sostener esta hipótesis en lo general. Con todo, ciertos aspectos del pensamiento cristero merecen todavía que se profundice en este sentido. Llama la atención un documento muy relevante, aunque quizás todavía muy poco conocido, la llamada "Constitución de los Cristeros", escrita al final de 1927 y firmada por 5500 cristeros de Michoacán y de los Altos de Jalisco, que tenía la intención de remplazar la

${ }^{24}$ Pío XI, Carta encíclica Firmissimam constantiam sobre la situación religiosa de México, Ciudad del Vaticano, 28 de marzo de 1937, en <http://w2.vatican.va/content/pius-xi/it/encyclicals/ documents/hf_p-xi_enc_19370328_firmissimam-constantiam.html $>$, consultado el 8 de marzo de 2018. En otros pasajes de la encíclica se habla explícitamente de "libertad religiosa". Se debe a la labor desempeñada por el episcopado estadounidense y sus expertos, particularmente el jesuita John Courtney Murray, la inclusión de la "encíclica mexicana" en las fuentes de la declaración conciliar. Cfr. John Courtney Murray, "The problem of religious freedom”, en Theological Studies, 25 (1964), pp. 503-575. Para una mirada sobre la redacción del documento conciliar véase Silvia Scatena, La fatica della libertà. L'elaborazione della dichiarazione Dignitatis humanae sulla libertà religiosa del Vaticano II, 2003, Boloña, Il Mulino. 
Constitución de Querétaro de 1917. Este documento, que está guardado en los archivos de la UNAM, fue publicado por primera vez en 1963 por Vicente Lombardo Toledano, ${ }^{25}$ líder histórico de la Confederación de Trabajadores de México, con un largo ensayo introductorio en el que describe a la Constitución de los Cristeros como un documento "fascista" y que además es una muy buena síntesis de las narrativas anticlericales producidas en México en todo el siglo XX. ${ }^{26}$ A pesar de los juicios sumariamente críticos de Lombardo Toledano, que entiende el documento, de manera muy imprecisa, como representativo del pensamiento de todo el catolicismo mexicano, ${ }^{27}$ en un artículo de esa constitución se manifiesta una actitud frente al tema de la libertad religiosa que, a mi modo de ver, es más moderna que la posición de la jerarquía eclesiástica de aquel tiempo. Se trata del artículo 64:

En la República Mexicana en lo sucesivo se disfrutará de la más amplia y completa libertad para todo lo que sea licito. En materia de religión, esta Constitución imparte a todas las iglesias y asociaciones religiosas todas las garantías a que tienen derecho y NINGUNA [sic] autoridad o funcionario público, ni persona alguna, podrá impedir el libre ejercicio de su religión a ninguna persona habitante de la Republica. Las autoridades federales, municipales, judiciales, administrativas y militares, observarán y harán que se observe, según su competencia y facultades, estricta y efi-

${ }^{25}$ Lombardo Toledano, La Constitución de los Cristeros, 1963, México, pp. 57-197. Hay una edición más reciente del texto en Enrique Lira-Gustavo Villanueva, La Constitución de los Cristeros y otros documentos, 2005, México, Universidad Nacional Autónoma de México-Centro de Estudios sobre la Universidad.

${ }^{26}$ Destaca, por ejemplo, la afirmación de que el fascismo "recurre al apoyo de la Iglesia, porque esta ha sido y sigue siendo la adversaria de todos los cambios profundos en la estructura de la sociedad humana. Por eso también le otorga derechos excepcionales y le reconoce la facultad de formar la conciencia de la niñez y de la juventud, para impedir que se conviertan, llegado el momento, en fuerzas renovadoras del sistema social establecido. [...] La Constitución de los Cristeros es una concepción corporativa, típicamente fascista, del Estado. Una Constitución contrarrevolucionaria que se levanta contra los frutos mayores de las Leyes de Reforma y de la Constitución de 1917, sin cuyas normas hubiera sido imposible el desarrollo progresivo de México". Lombardo Toledano, op. cit., p. 47.

${ }^{27}$ Según el autor, la Constitución de los Cristeros “tiene una importancia indudable, porque expresa el verdadero pensamiento de los jerarcas de la Iglesia acerca de lo que, a su juicio, debe ser el régimen político de nuestro país si llegaran a alcanzar el poder”; ibid., p. 30. 
cazmente este mandato. Los ministros de las religiones serán considerados como personas que ejercen una profesión licita. El ministerio sacerdotal o religioso, en manera alguna podrá ser obstáculo para el ejercicio del magisterio en ninguno de sus ramos y categorías. ${ }^{28}$ La libertad religiosa y de cultos y ceremonias dentro de los templos y los hogares, es absoluta. No se podrán dictar, ni aprobar leyes, que restrinjan, reglamenten o prohíban religión alguna. ${ }^{29}$

A pesar de la probablemente escasa representatividad de este documento respecto del conjunto de la Iglesia católica en México, no es ocioso opinar que el asunto de la lucha religiosa mexicana pueda haber favorecido el comienzo —o la continuación en algunos casos— de un trabajo de revisión de antiguos esquemas que dio sus frutos maduros en la estación conciliar. Las fuentes de archivo de la Santa Sede ofrecen muchos datos para reflexionar. Por ejemplo, llama la atención que a partir de 1915 (paralelamente al debate en Estados Unidos sobre el reconocimiento internacional del gobierno de Venustiano Carranza $)^{30}$ la diplomacia vaticana mantuvo como norma de conducta ante la situación mexicana la defensa y la promoción de la "libertad religiosa", principio que encontraba en el contexto estadounidense un modelo de referencia casi obligado. ${ }^{31}$ La estrategia diplomática de la Santa Sede,

${ }^{28}$ Es el único párrafo del artículo que Lombardo Toledano menciona en su resumen del texto constitucional cristero (ibid., p. 40).

${ }^{29}$ Las cursivas son mías. Llama la atención que este artículo, según una tendencia común de la mayoría de las constituciones latinoamericanas desde la Independencia, se relaciona con la primera enmienda de la constitución estadounidense de 1787, que garantiza el libre ejercicio de la religión y veda las leyes que oficialicen una religión. Sobre la influencia de la constitución estadounidense en el extranjero, véase Albert J. Rosenthal-Louis Henkin, Constitutionalism and rights. The influence of the United States Constitution abroad, 1990, Nueva York, Columbia University Press. Para un examen de la contribución de América Latina a la reflexión filosófica y jurídica sobre los derechos humanos, véase Paolo Carozza, "From Conquest to Constitutions. Retrieving a Latin American Tradition of the Idea of Human Rights", Human Rights Quarterly, 25 (2003), pp. 281-313.

${ }^{30}$ Meyer, op. cit., pp. 27-33.

${ }^{31}$ Primero, la Secretaria de Estado envió una carta al cardenal James Gibbons de Baltimore para solicitar la intervención del presidente Woodrow Wilson en el asunto (carta del cardenal Gasparri al cardenal James Gibbons, 4 de agosto de 1915, Archivo Secreto Vaticano, Segr. Stato, 1915, rubr. 251, fasc. 7, f. 167r/v). Luego, el cardenal secretario de Estado Pietro Gasparri envió a los representantes pontificios en Río de Janeiro, Buenos Aires, Santiago de Chile, Madrid, Mónaco y Viena un telegrama cifrado en el que se hablaba de la necesidad de introducir en 
— que consistía en vincular el reconocimiento estadounidense del gobierno revolucionario al compromiso de Carranza de defender la libertad religiosa en México - fracasó ante el éxito de la conferencia panamericana de Washington (octubre de 1915), pero la idea de que la libertad religiosa, en el marco de una separación amistosa entre el Estado y la Iglesia, pudiese representar una solución aceptable en un país mayoritariamente católico empezaba a abrirse paso en el Vaticano. Destacan las reflexiones escritas en febrero de 1916 por el futuro pontífice Pío XII en un memorando interno de la Secretaría de Estado, en el que el entonces secretario para los Asuntos Eclesiásticos Extraordinarios monseñor Eugenio Pacelli afirmó que "las tendencias modernas hacia la separación del Estado y la Iglesia" habrían podido quizás garantizar la libertad de la Iglesia "en un futuro no muy lejano". ${ }^{32}$

El tema de la libertad religiosa se mantuvo central también en los años siguientes, debido al activismo diplomático de la Santa Sede y de grupos católicos estadounidenses en pro de la Iglesia mexicana perseguida. Cabe mencionar el papel desempeñado por el presidente de la Catholic Church Extension Society de Chicago, monseñor Francis Clement Kelley, que en la conferencia de paz de París (primavera de 1919), según las directivas acordadas con la Secretaría de Estado vaticana, quiso someter a la atención de los delegados de los varios países el proyecto de una cláusula en defensa de la libertad religiosa, para introducirla en el pacto constitutivo de la Sociedad de las Naciones. ${ }^{33}$

En los años del conflicto armado cristero, varios prelados se expresaron positivamente sobre el modelo estadounidense de separación entre el Estado y la Iglesia, entre ellos el delegado apostólico en Washington Pietro Fumasoni-Biondi y el obispo de Tabasco Pascual Díaz y Barreto,

México la "plena libertad religiosa como en Estados Unidos" (Archivo Secreto Vaticano, Segr. Stato, 1915, rubr. 251, fasc. 7, f. 171r).

${ }^{32}$ Voto de monseñor Eugenio Pacelli, 20 de febrero de 1916, publicado en Romeo Astorri, "Diritto comune e normativa concordataria. Uno scritto inedito di mons. Pacelli sulla 'decadenza' degli accordi tra Chiesa e Stato”, en Storia contemporanea, XXII (1991), núm. 4, p. 699.

${ }^{33}$ Un primer esbozo de la cuestión se encuentra en Paolo Valvo, "De Querétaro a Versalles. La Santa Sede y la Constitución mexicana (1917-1920)", en Miguel Carbonell Sánchez y Óscar Cruz Barney (coords.), Historia y Constitución. Homenaje a José Luis Soberanes Fernández, t. III, 2015, México, Universidad Nacional Autónoma de México, pp. 393-435. 
el cual, en un ensayo de abril de 1928 publicado en los Estados Unidos (donde el prelado se hallaba exilado desde el comienzo de 1927) afirmó, primero, que la doctrina de la Iglesia no imponía la unión de la Iglesia con el Estado en países donde no existía la unidad religiosa, como el México de aquel entonces, lo que parece una afirmación significativa si se toma en cuenta que el país tenía todavía un porcentaje de católicos superior al 90\%. Además, dijo que los obispos mexicanos aceptaban la separación como solución práctica. ${ }^{34}$

Por su parte, el delegado apostólico Fumasoni-Biondi, un mes después de la publicación del artículo del obispo de Tabasco, en un largo memorando a la Secretaría de Estado subrayó, adoptando un punto de vista histórico, que los católicos mexicanos no habían aprovechado las oportunidades que les había presentado la evolución política y social del país, como cuando, en 1857, no se dieron cuenta de que "había llegado el tiempo de aceptar, al menos en hipótesis, sin renunciar a las tradiciones católicas, las teorías liberales de la separación entre la Iglesia y el Estado con todas sus consecuencias. De esta manera quizás la Iglesia podría haberse liberado de la persecución y los católicos tener la oportunidad de ejercerse en la vida política, como ocurrió en Brasil después de la caída del Imperio. Así podría haber una separación más o menos como en Estados Unidos". ${ }^{35}$

Las reflexiones de Fumasoni-Biondi, si por un lado confirmaban la actitud de la diplomacia pontificia a favor de la libertad religiosa en México, por otro lado parecían más avanzadas respecto al horizonte "constantiniano" que en aquel entonces compartían todavía la Curia romana - donde el conjunto del magisterio de Pio XI (como en la encíclica Quas primas) ${ }^{36}$ y la renovada actividad concordataria de la Santa

${ }^{34}$ Pascual Díaz, "State vs. Church in Mexico", The North American Review, 1928, núm. 842, pp. 401-408.

${ }^{35}$ Memorando de monseñor Pietro Fumasoni-Biondi dirigido al cardenal Pietro Gasparri, mayo de 1928, Secretaría de Estado, Sección para las relaciones con los Estados, Archivo Histórico, Archivo de la Congregación para los Asuntos Eclesiásticos Extraordinarios, Messico, pos. 521 (P.O.), fasc. 228, f. 54, p. 16.

${ }^{36}$ En la encíclica, que instituía para toda la Iglesia la fiesta anual de Cristo Rey, el pontífice afirmaba: "Juzgamos peste de nuestros tiempos al llamado laicismo con sus errores y abominables intentos; y vosotros sabéis, venerables hermanos, que tal impiedad no maduró en un solo día, sino que se incubaba desde mucho antes en las entrañas de la sociedad. Se comenzó por negar el 
Sede hacían de Estados Unidos una positiva excepción más que un modelo para exportar - y la jerarquía eclesiástica mexicana. Es ilustrativo el caso del arzobispo de Morelia Leopoldo Ruiz y Flores, el cual, en una carta al secretario de Estado Gasparri del 3 de noviembre de 1929, se mostraba convencido de que el trabajo desempeñado por los católicos mexicanos en el marco de la nueva acción católica habría apresurado "el Constantino primero y el Teodosio después para el pobre México". 37

Las alusiones del arzobispo al Edicto de Milán de 313, con el que Constantino había garantizado la plena libertad religiosa a todos los súbditos del imperio romano, ${ }^{38} \mathrm{y}$ al Edicto de Tesalónica de 380, del imperador Teodosio, que impuso al contrario el cristianismo como única religión del Estado, ayudan a comprender la dificultad que la jerarquía eclesiástica mexicana — en conformidad con una actitud prevalente en el catolicismo latino en la primera mitad del siglo XX — tenía en reconocer a todos los mismos derechos que con razón reivindicaba para los católicos, dificultad que, en ciertos casos, parece haber sobrevivido hasta tiempos recientes, como lo muestra la actitud de algunos obispos frente a la reforma constitucional del régimen de Carlos Salinas de Gortari. Esta postura de la Iglesia ha ofrecido muchas veces, en la historia contemporánea de México, una justificación a quienes se han opuesto al reconocimiento de derechos a las confesiones religiosas, ya que la pretensión de la Iglesia católica de representar la única fe verdadera (que

imperio de Cristo sobre todas las gentes; se negó a la Iglesia el derecho, fundado en el derecho del mismo Cristo, de enseñar al género humano, esto es, de dar leyes y de dirigir los pueblos para conducirlos a la eterna felicidad. Después, poco a poco, la religión cristiana fue igualada con las demás religiones falsas y rebajada indecorosamente al nivel de estas. Se la sometió luego al poder civil y a la arbitraria permisión de los gobernantes y magistrados. Y se avanzó más: hubo algunos de estos que imaginaron sustituir la religión de Cristo con cierta religión natural, con ciertos sentimientos puramente humanos. No faltaron Estados que creyeron poder pasarse sin Dios, y pusieron su religión en la impiedad y en el desprecio de Dios". Pío XI, Carta encíclica Quas primas sobre la fiesta de Cristo Rey, Roma, 11 de diciembre de 1925, § 23, en <http:// w2.vatican.va/content/pius-xi/es/encyclicals/documents/hf_p-xi_enc_11121925_quas-primas. html>, consultado el 8 de marzo de 2018.

${ }^{37}$ Carta de monseñor Ruiz y Flores al cardenal Pietro Gasparri, 3 de noviembre de 1929, Archivo Secreto Vaticano, Arch. Deleg. Messico, busta 49, fasc. 255, f. 58r/v.

${ }^{38}$ Véase Alberto De la Hera, "La libertad religiosa en sus orígenes históricos", en Carbonell Sánchez y Cruz Barney, op. cit., pp. 229-256. 
el Concilio Vaticano II, sin embargo, no niega bajo el perfil teológico) podía ser vista equivocadamente como una amenaza a la laicidad del Estado. ${ }^{39}$

Si bien es cierto que la Iglesia católica tiene que enfrentarse constantemente y sin reservas al desafío de la libertad religiosa en una sociedad no confesional sino pluralista, esto no exime al Estado y a la llamada "cultura laica" de la responsabilidad de reconocer, a su vez, sus propias faltas en el trato que han reservado al derecho de libertad religiosa - cuya dimensión pública sería anacrónico negar hoy, como lo hicieron hace cien años los constituyentes de Querétaro- mediante un análisis desapasionado de la historia nacional.

El caso mexicano demuestra con toda evidencia la importancia de un conocimiento crítico de la historia al establecer las premisas para una sociedad más abierta hacia el fenómeno religioso. En este sentido, no cabe duda de que la reforma constitucional de 1992 representó un paso sustancial hacia una mayor libertad religiosa y contribuyó a la larga transición democrática del país. Hoy, sin embargo, este avance jurídico corre el riesgo de perder sentido, sobre todo entre las jóvenes generaciones, cuya educación se ve afectada todavía muchas veces por los viejos prejuicios de las narrativas históricas anticlericales, que siguen alimentando un laicismo hostil hacia el fenómeno religioso. Esto representa una amenaza para la cohesión social del país, en una coyuntura histórica en la que la sociedad civil mexicana padece ya por los complejos problemas socioeconómicos del tiempo presente, que aquejan también a otros países americanos y europeos.

${ }^{39}$ Así opina José Luis Lamadrid Sauza, quizás el principal exponente de la que podríamos llamar la "narrativa histórica gubernamental" con respecto a la reforma constitucional salinista: "El problema estriba en que toda religión, en principio, postula la verdad absoluta y permanente de su orden moral, otorgándole a este, consciente o inconscientemente, primacía sobre un orden jurídico positivo que por definición es relativo y mutable. De aquí surgen no pocas de las tensiones entre religión y derecho, así como también entre iglesias y Estado. Si bien es cierto que las distintas agrupaciones religiosas adoptan posturas disímbolas en cuando al grado de intolerancia respecto a sistemas normativos ajenos, resulta incuestionable el que históricamente la Iglesia católica se haya significado como una de las más intransigentes". A esto contribuye, siempre según el mismo autor, el hecho de que "la Iglesia católica reclama para sí el título de 'sociedad perfecta', se concibe a sí misma como dotada de todos los poderes, derechos y otros medios necesarios para alcanzar su fin, siendo por tanto autosuficiente y autónoma en su propio orden”. Lamadrid, op. cit., pp. 208, 214. 
Se prohíbe su reproducción total o parcial por cualquier medio, incluido electrónico, sin permiso previo y por escrito de los editores. 